\title{
Design Artificial Intelligent Parallel Feedback Linearization of PID Control with Application to Continuum Robot
}

\author{
Farzin Piltan ${ }^{\mathrm{a}}$, Sara Emamzadeh ${ }^{\mathrm{b}}$, Sara Heidari $^{\mathrm{b}}$, Samaneh Zahmatkesh $^{\mathrm{b}}$, Kamran Heidari $^{\mathrm{b}}$ \\ ${ }^{a}$ Senior Researcher at Research and Development Department of SanatkadeheSabze Pasargad Company \\ (S.S.P. Co), Shiraz, Iran \\ ${ }^{b}$ Research and Development Unit, SanatkadeheSabze Pasargad Company (S.S.P. Co), Shiraz, Iran
}

\begin{abstract}
Refer to this research, an intelligent robust fuzzy parallel feedback linearization estimator for ProportionalIntegral-Derivative (PID) controller is proposed for highly nonlinear continuum robot manipulator. In the absence of robot knowledge, PID may be the best controller, because it is model-free, and its parameters can be adjusted easily and separately. And it is the most used in robot manipulators. In order to remove steadystate error caused by uncertainties and noise, the integrator gain has to be increased. This leads to worse transient performance, even destroys the stability. The integrator in a PID controller also reduces the bandwidth of the closed-loop system. Model-based compensation for PD control is an alternative method to substitute PID control. Feedback linearization compensation is one of the nonlinear compensator. The first problem of the pure feedback linearization compensator (FLC) was equivalent problem in certain and uncertain systems. The nonlinear equivalent dynamic problem in uncertain system is solved by using parallel fuzzy logic theory. To eliminate the continuum robot manipulator system's dynamic; Mamdani fuzzy inference system is design and applied to FLC. This methodology is based on design parallel fuzzy inference system and applied to equivalent nonlinear dynamic part of FLC. The results demonstrate that the model free fuzzy FLC estimator works well to compensate linear PID controller in presence of partly uncertainty system (e.g., continuum robot).
\end{abstract}

Index Terms: Fuzzy inference system, Mamdani fuzzy inference engine, feedback linearization estimator, continuum robot, linear PID theory.

(C) 2013 Published by MECS Publisher. Selection and/or peer review under responsibility of the Research Association of Modern Education and Computer Science.

\section{Introduction}

In the absence of robot knowledge, proportional-integral-derivative (PID) may be the best controller, because it is model-free, and its parameters can be adjusted easily and separately [1]. And it is the most used

* Corresponding author.

E-mail address: ${ }^{* 1}$ piltan_f@iranssp.com; ${ }^{* 2}$ ssp.robotic@gmail.com 
in continuum robot manipulators. In order to remove steady-state error caused by uncertainties and noise, the integrator gain has to be increased. This leads to worse transient performance, even destroys the stability. The integrator in a PID controller also reduces the bandwidth of the closed-loop system. PD control guarantees stability only when the PD gains tend to infinity, the tracking error does not tend to zero when friction and gravity forces are included in the continuum robot manipulator dynamics [2]. Model-based compensation for PD control is an alternative method to substitute PID control [1], such as adaptive gravity compensation [3], desired gravity compensation [2], and PD+ with position measurement [4]. They all needed structure information of the robot gravity. Some nonlinear PD controllers can also achieve asymptotic stability, for example PD control with time-varying gains [5], PD control with nonlinear gains [6], and PD control with feedback linearization compensation [7-8]. But these controllers are complex, many good properties of the linear PID control do not exist because these controllers do not have the same form as the industrial PID. When the friction and gravity forces are unknown, both fuzzy logic and feedback linearization techniques can compensate them [9-15]. A fuzzy-adaptive controller by using a fuzzy inference engine plus a servo feedback control was proposed in [10]. A hybrid neuro control for robot tracking was discussed in [11-23], where static neural networks are used to learn mass matrix, centrifugal and Coriolis forces. Because they used the theory of function approximation, the algorithms are sensitive to the training data and local minima. Due to fuzzy modeling error, fuzzy controllers cannot assure that the regulation errors are asymptotically stable.

Feed-back linearization compensator (FLC) is a powerful nonlinear estimator which it widely used in control of robot manipulator. It is based on feedback linearization and computes the required arm torques using the nonlinear feedback control law. This controller/estimator works very well when all dynamic and physical parameters are known but when the continuum robot manipulator has variation in dynamic parameters, the controller/estimator has no acceptable performance[7-14]. In practice, most of continuum robot manipulator systems parameters are unknown or time variant, therefore, artificial intelligence based feedback linearization estimator is used to compensate dynamic equation of continuum robot manipulator[1, 6]. Research on FLC is significantly growing on robot manipulator application which has been reported in [1, 6, 15-20]. Vivas and Mosquera [19]have proposed a predictive functional controller and compare to FLC for tracking response in uncertain environment. However both controllers have been used in feedback linearization, but predictive strategy gives better result as a performance. A FLC with non parametric regression models have been presented for a robot arm[16]. This controller also has been problem in uncertain dynamic models. Based on [7- 11] and [18-29] FLC is a significant nonlinear estimator/controller to certain systems which it is based on feedback linearization and computes the required arm torques using the nonlinear feedback control law. When all dynamic and physical parameters are known, FLC works fantastically; practically a large amount of systems have uncertainties, therefore artificial intelligence methodology applied to FLC to estimate the nonlinear equivalent part based on parallel methodology.

Fuzzy-logic aims to provide an approximate but effective means of describing the behavior of systems that are not easy to describe precisely, and which are complex or ill-defined. It is based on the assumption that, in contrast to Boolean logic, a statement can be partially true (or false). For example, the expression (I live near SSP) where the fuzzy value (near) applied to the fuzzy variable (distance), in addition to being imprecise, is subject to interpretation. The essence of fuzzy control is to build a model of human expert who is capable of controlling the plant without thinking in terms of its mathematical model. As opposed to conventional control approaches where the focus is on constructing a controller described by differential equations, in fuzzy control the focus is on gaining an intuitive understanding (heuristic data) of how to best control the process, and then load this data into the control system [24-46].

Continuum robots represent a class of robots that have a biologically inspired form characterized by flexible backbones and high degrees-of-freedom structures [1]. The idea of creating "trunk and tentacle" robots, (in recent years termed continuum robots [1]), is not new [2]. Inspired by the bodies of animals such as snakes [3], the arms of octopi [4], and the trunks of elephants [5], [6], researchers have been building prototypes for many years. A key motivation in this research has been to reproduce in robots some of the 
special qualities of the biological counterparts. This includes the ability to "slither" into tight and congested spaces, and (of particular interest in this work) the ability to grasp and manipulate a wide range of objects, via the use of "whole arm manipulation" i.e. wrapping their bodies around objects, conforming to their shape profiles. Hence, these robots have potential applications in whole arm grasping and manipulation in unstructured environments such as rescue operations. Theoretically, the compliant nature of a continuum robot provides infinite degrees of freedom to these devices. However, there is a limitation set by the practical inability to incorporate infinite actuators in the device. Most of these robots are consequently underactuated (in terms of numbers of independent actuators) with respect to their anticipated tasks. In other words they must achieve a wide range of configurations with relatively few control inputs. This is partly due to the desire to keep the body structures (which, unlike in conventional rigid-link manipulators or fingers, are required to directly contact the environment) "clean and soft", but also to exploit the extra control authority available due to the continuum contact conditions with a minimum number of actuators. For example, the Octarm VI continuum manipulator, discussed frequently in this paper, has nine independent actuated degrees-of-freedom with only three sections. Continuum manipulators differ fundamentally from rigid-link and hyper-redundant robots by having an unconventional structure that lacks links and joints. Hence, standard techniques like the Denavit-Hartenberg (D-H) algorithm cannot be directly applied for developing continuum arm kinematics. Moreover, the design of each continuum arm varies with respect to the flexible backbone present in the system, the positioning, type and number of actuators. The constraints imposed by these factors make the set of reachable configurations and nature of movements unique to every continuum robot. This makes it difficult to formulate generalized kinematic or dynamic models for continuum robot hardware. Chirikjian and Burdick were the first to introduce a method for modeling the kinematics of a continuum structure by representing the curve-shaping function using modal functions [6]. Mochiyama used the Serret- Frenet formulae to develop kinematics of hyper-degrees of freedom continuum manipulators [5]. For details on the previously developed and more manipulator-specific kinematics of the Rice/Clemson "Elephant trunk" manipulator, see [1-5]. For the Air Octor and Octarm continuum robots, more general forward and inverse kinematics have been developed by incorporating the transformations of each section of the manipulator (using D-H parameters of an equivalent virtual rigid link robot) and expressing those in terms of the continuum manipulator section parameters [4]. The net result of the work in [6-9] is the establishment of a general set of kinematic algorithms for continuum robots. Thus, the kinematics (i.e. geometry based modeling) of a quite general set of prototypes of continuum manipulators has been developed and basic control strategies now exist based on these. The development of analytical models to analyze continuum arm dynamics (i.e. physicsbased models involving forces in addition to geometry) is an active, ongoing research topic in this field. From a practical perspective, the modeling approaches currently available in the literature prove to be very complicated and a dynamic model which could be conveniently implemented in an actual device's real-time controller has not been developed yet. The absence of a computationally tractable dynamic model for these robots also prevents the study of interaction of external forces and the impact of collisions on these continuum structures. This impedes the study and ultimate usage of continuum robots in various practical applications like grasping and manipulation, where impulsive dynamics [1-4] are important factors. Although continuum robotics is an interesting subclass of robotics with promising applications for the future, from the current state of the literature, this field is still in its stages of inception.

This paper is organized as follows; section 2, is served as an introduction to the PID controller, feedback linearization compensator, Mamdani fuzzy inference engine to estimate the FLC and its application to control of continuum robot and dynamic of continuum robot. Part 3, introduces and describes the methodology. Section 4 presents the simulation results and discussion of this algorithm applied to a continuum robot and the final section is describing the conclusion. 


\section{Theory}

\subsection{Dynamic Formulation of Continuum Robot}

The Continuum section analytical model developed here consists of three modules stacked together in series. In general, the model will be a more precise replication of the behavior of a continuum arm with a greater of modules included in series. However, we will show that three modules effectively represent the dynamic behavior of the hardware, so more complex models are not motivated. Thus, the constant curvature bend exhibited by the section is incorporated inherently within the model. The mass of the arm is modeled as being concentrated at three points whose co-ordinates referenced with respect to (see Figure 1);

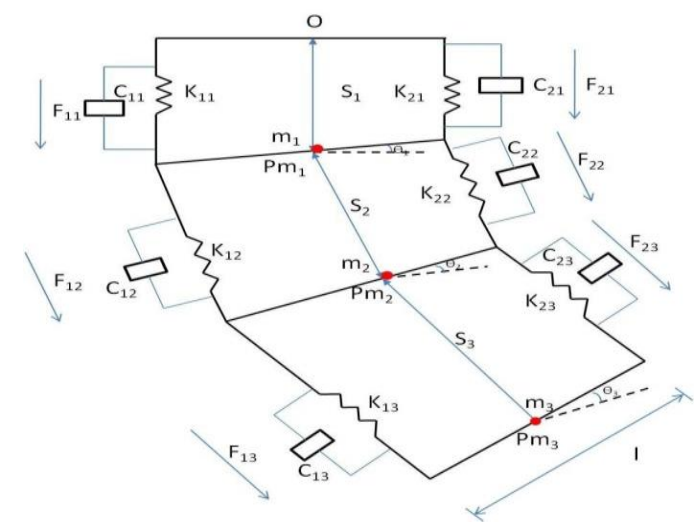

Fig 1: Assumed structure for analytical model of a section of a continuum arm

Where;

$l$ - Length of the rigid rod connecting the two struts, constant throughout the structure

$k_{1, i}, i=1,2,3$ - Spring constant of actuator 1 at module $i$

$k_{2, i}, i=1,2,3$ - Spring constant of actuator 2 at module $i$

$C_{1, i}, i=1,2,3$ - Damping coefficient of actuator 1 at module $i$

$C_{2, i}, i=1,2,3$ - Damping coefficient of actuator 2 at module $i$

$m_{i}, i=1,2,3$ - Mass in each module

$I_{i}, i=1,2,3$ - Moment of inertia of the rigid rod in each module.

A global inertial frame $(\mathrm{N})$ located at the base of the arm are given below

$$
{ }_{m 1}^{N} P=S_{1} \cdot \widehat{n_{3}}
$$




$$
\begin{aligned}
&{ }_{m 2}^{N} P= S_{2} \cdot \sin \theta_{1} \widehat{n_{1}}+\left(S_{1}+S_{2} \cos \theta_{1}\right) \cdot \widehat{n_{3}} \\
&{ }_{m 3}^{N} P=\left(S_{2} \cdot \sin \theta_{1}+S_{3} \cdot \sin \left(\theta_{1}+\theta_{2}\right)\right) \widehat{n_{1}} \\
&\left.\quad+\left(S_{1}+S_{2} \cos \theta_{1}+S_{3} \cdot \cos \left(\theta_{1}+\theta_{2}\right)\right)\right) \cdot \widehat{n_{3}}
\end{aligned}
$$

The position vector of each mass is initially defined in a frame local to the module in which it is present. These local frames are located at the base of each module and oriented along the direction of variation of coordinate ' $s$ ' of that module. The positioning of each of these masses is at the centre of mass of the rigid rods connecting the two actuators. Differentiating the position vectors we obtain the linear velocities of the masses. The kinetic energy $(\mathrm{T})$ of the system comprises the sum of linear kinetic energy terms (constructed using the above velocities) and rotational kinetic energy terms due to rotation of the rigid rod connecting the two

$$
\begin{aligned}
T=(0.5) m_{1} \dot{s}_{1}^{2} & +(0.5) m_{2}\left(\left(\dot{s}_{2} \sin \theta_{1}+s_{2} \cos \theta_{1} \dot{\theta}_{1}\right)^{2}+\left(\dot{s}_{1}+\dot{s}_{2} \cos \theta_{1}-s_{2} \sin \theta_{1} \dot{\theta}_{1}\right)^{2}\right) \\
& +(0.5) m_{3}\left(\left(\dot{s}_{2} \sin \theta_{1}+s_{2} \cos \theta_{1} \dot{\theta}_{1}+\dot{s}_{3} \sin \left(\theta_{1}+\theta_{2}\right)+s_{3} \cos \left(\theta_{1}+\theta_{2}\right) \dot{\theta}_{1}\right.\right. \\
& \left.+s_{3} \cos \left(\theta_{1}+\theta_{2}\right) \dot{\theta}_{2}\right)^{2} \\
& \left.+\left(\dot{s}_{1}+\dot{s}_{2} \cos \theta_{1}-s_{2} \sin \theta_{1} \dot{\theta}_{1}+\dot{s}_{3} \cos \left(\theta_{1}+\theta_{2}\right)-s_{3} \sin \left(\theta_{1}+\theta_{2}\right) \dot{\theta}_{1}-s_{3} \sin \left(\theta_{1}+\theta_{2}\right) \dot{\theta}_{2}\right)^{2}\right) \\
& +(0.5) I_{1} \dot{\theta}_{1}{ }^{2}+(0.5) I_{2}\left(\dot{\theta}_{1}{ }^{2}+\dot{\theta}_{2}{ }^{2}\right) \\
& +(0.5) I_{3}\left(\dot{\theta}_{1}{ }^{2}+\dot{\theta}_{2}{ }^{2}\right. \\
& \left.+\dot{\theta}_{3}{ }^{2}\right) .
\end{aligned}
$$

actuators, and is given below as

The potential energy (P) of the system comprises the sum of the gravitational potential energy and the spring potential energy. A small angle assumption is made throughout the derivation. This allows us to directly express the displacement of springs and the velocities associated with dampers in terms of system generalized coordinates.

$$
\begin{aligned}
P=-m_{1} g s_{1}- & m_{2} g\left(s_{1}+s_{2} \cos \theta_{1}\right)-m_{3} g\left(s_{1}+s_{2} \cos \theta_{1}+s_{3} \cos \left(\theta_{1}+\theta_{1}\right)\right)+(0.5) k_{11}\left(s_{1}+\left(\frac{1}{2}\right) \theta_{1}-s_{01}\right)^{2} \\
& +(0.5) k_{21}\left(s_{1}+(1 / 2) \theta_{1}-s_{01}\right)^{2}+(0.5) k_{12}\left(s_{2}+(1 / 2) \theta_{2}-s_{02}\right)^{2} \\
& +(0.5) k_{22}\left(s_{2}+(1 / 2) \theta_{2}-s_{02}\right)^{2}+(0.5) k_{13}\left(s_{3}+(1 / 2) \theta_{3}-s_{03}\right)^{2} \\
& +(0.5) k_{23}\left(s_{3}+(1 / 2) \theta_{3}-s_{03}\right)^{2}
\end{aligned}
$$

where, $S_{01}, S_{02}, S_{03}$ are the initial values of $S_{1}, S_{2}, S_{3}$ respectively.

Due to viscous damping in the system, Rayliegh's dissipation function [6] is used to give damping energy 


$$
\begin{aligned}
D=(0.5) c_{11}\left(\dot{s}_{1}\right. & \left.+\left(\frac{1}{2}\right) \dot{\theta}_{1}\right)^{2}+(0.5) c_{21}\left(\dot{s}_{1}+\left(\frac{1}{2}\right) \dot{\theta}_{1}\right)^{2}+(0.5) c_{12}\left(\dot{s}_{2}+\left(\frac{1}{2}\right) \dot{\theta}_{2}\right)^{2}+(0.5) c_{22}\left(\dot{s}_{2}+\left(\frac{1}{2}\right) \dot{\theta}_{2}\right)^{2} \\
& +(0.5) c_{13}\left(\dot{s}_{3}+\left(\frac{1}{2}\right) \dot{\theta}_{3}\right)^{2}+(0.5) c_{23}\left(\dot{s}_{3}+\left(\frac{1}{2}\right) \dot{\theta}_{3}\right)^{2}
\end{aligned}
$$

The generalized forces in the system corresponding to the generalized co-ordinates are expressed as appropriately weighted combinations of the input forces.

$$
\begin{aligned}
& Q_{s_{1}}=F_{11}+F_{21}+\left(F_{12}+F_{22}\right) \cos \theta_{1}+\left(F_{13}+F_{23}\right) \cos \left(\theta_{1}+\theta_{2}\right) \\
& Q_{s_{2}}=F_{12}+F_{22}+\left(F_{13}+F_{23}\right) \cos \left(\theta_{2}\right) \\
& Q_{s_{3}}=F_{13}+F_{23} \\
& Q_{\theta_{1}}=(1 / 2)\left(F_{11}-F_{21}\right)+(1 / 2)\left(F_{12}-F_{22}\right)+(1 / 2)\left(F_{13}-F_{23}\right)+s_{2} \sin \theta_{2}\left(F_{13}+F_{23}\right) \\
& Q_{\theta_{1}}=(1 / 2)\left(F_{12}-F_{22}\right)+(1 / 2)\left(F_{13}-F_{23}\right) \\
& Q_{\theta_{1}}=(1 / 2)\left(F_{13}-F_{23}\right)
\end{aligned}
$$

It can be evinced from the force expressions that the total input forces acting on each module can be resolved into an additive component along the direction of extension and a subtractive component that results in a torque. For the first module, there is an additional torque produced by forces in the third module.

The model resulting from the application of Lagrange's equations of motion obtained for this system can be represented in the form

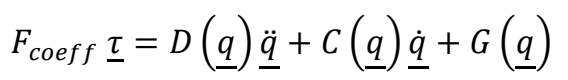

where $\tau$ is a vector of input forces and $\mathrm{q}$ is a vector of generalized co-ordinates. The force coefficient matrix $F_{\text {coeff }}$ transforms the input forces to the generalized forces and torques in the system. The inertia matrix, $D$ is composed of four block matrices. The block matrices that correspond to pure linear accelerations and pure angular accelerations in the system (on the top left and on the bottom right) are symmetric. The matrix $C$ contains coefficients of the first order derivatives of the generalized co-ordinates. Since the system is nonlinear, many elements of $C$ contain first order derivatives of the generalized co-ordinates. The remaining terms in the dynamic equations resulting from gravitational potential energies and spring energies are collected in the matrix $G$. The coefficient matrices of the dynamic equations are given below, 
Fcoeff $=\left[\begin{array}{cccccc}1 & 1 & \cos \left(\theta_{1}\right) & \cos \left(\theta_{1}\right) & \cos \left(\theta_{1}+\theta_{2}\right) & \cos \left(\theta_{1}+\theta_{2}\right) \\ 0 & 0 & 1 & 1 & \cos \left(\theta_{2}\right) & \cos \left(\theta_{2}\right) \\ 0 & 0 & 0 & 0 & 1 & 1 \\ 1 / 2 & -1 / 2 & 1 / 2 & -1 / 2 & 1 / 2+s_{2} \sin \left(\theta_{2}\right) & -1 / 2+s_{2} \sin \left(\theta_{2}\right) \\ 0 & 0 & 1 / 2 & -1 / 2 & 1 / 2 & -1 / 2 \\ 0 & 0 & 0 & 0 & 1 / 2 & -1 / 2\end{array}\right]$

$D(\underline{q})=$

$\left[\begin{array}{cccccc}m_{1}+m_{2} & m_{2} \cos \left(\theta_{1}\right) & & -m_{2} s_{2} \sin \left(\theta_{1}\right) & \\ +m_{3} & +m_{3} \cos \left(\theta_{1}\right) & m_{3} \cos \left(\theta_{1}+\theta_{2}\right) & -m_{3} s_{2} \sin \left(\theta_{1}\right) & -m_{3} s_{3} \sin \left(\theta_{1}+\theta_{2}\right) & 0 \\ & & & -m_{3} s_{3} \sin \left(\theta_{1}+\theta_{2}\right) & \\ m_{2} \cos \left(\theta_{1}\right) & m_{2}+m_{3} & m_{3} \cos \left(\theta_{2}\right) & -m_{3} s_{3} \sin \left(\theta_{2}\right) & -m_{3} s_{3} \sin \left(\theta_{2}\right) & 0 \\ +m_{3} \cos \left(\theta_{1}\right) & & & & \\ m_{3} \cos \left(\theta_{1}+\theta_{2}\right) & m_{3} \cos \left(\theta_{2}\right) & m_{3} & m_{3} s_{3} \sin \left(\theta_{2}\right) & 0 & 0 \\ -m_{2} s_{2} \sin \left(\theta_{1}\right) & & & m_{2} s_{2}^{2}+I_{1}+I_{2} & I_{2}+m_{3} s_{3}^{2}+I_{3} & I_{3} \\ -m_{3} s_{2} \sin \left(\theta_{1}\right) & -m_{3} s_{3} \sin \left(\theta_{2}\right) & m_{3} s_{2} \sin \left(\theta_{2}\right) & +I_{3}+m_{3} s_{2}^{2}+m_{3} s_{3}^{2} & +m_{3} s_{3} \cos \left(\theta_{2}\right) s_{2} & \\ -m_{3} s_{3} \sin \left(\theta_{1}+\theta_{2}\right) & & & +2 m_{3} s_{3} \cos \left(\theta_{2}\right) s_{2} & & \\ -m_{3} s_{3} \sin \left(\theta_{1}+\theta_{2}\right) & -m_{3} s_{3} \sin \left(\theta_{2}\right) & 0 & I_{2}+m_{3} s_{3}^{2}+I_{3} & I_{2}+m_{3} s_{3}^{2}+I_{3} & I_{3} \\ 0 & 0 & 0 & +m_{3} s_{3} \cos \left(\theta_{2}\right) s_{2} I & & I_{3}\end{array}\right]$




$$
\begin{aligned}
& C(\underline{q})
\end{aligned}
$$

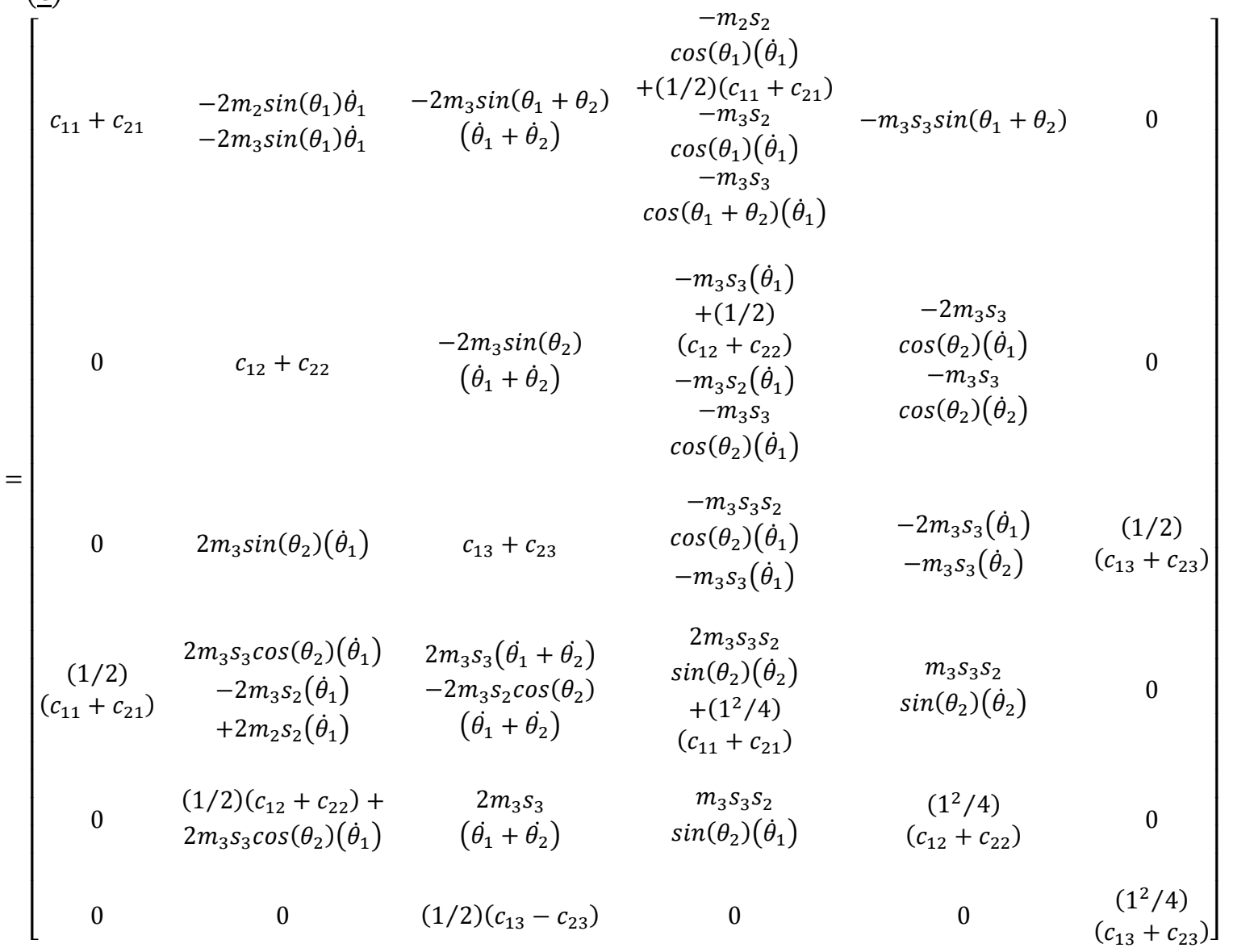

$$
G(\underline{q})=\left[\begin{array}{c}
-m_{1} g-m_{2} g+k_{11}\left(s_{1}+(1 / 2) \theta_{1}-s_{01}\right)+k_{21}\left(s_{1}-(1 / 2) \theta_{1}-s_{01}\right)-m_{3} g \\
-m_{2} g \cos \left(\theta_{1}\right)+k_{12}\left(s_{2}+(1 / 2) \theta_{2}-s_{02}\right)+k_{22}\left(s_{2}-(1 / 2) \theta_{2}-s_{02}\right)-m_{3} g \cos \left(\theta_{1}\right) \\
-m_{3} g \cos \left(\theta_{1}+\theta_{2}\right)+k_{13}\left(s_{3}+(1 / 2) \theta_{3}-s_{03}\right)+k_{23}\left(s_{3}-(1 / 2) \theta_{3}-s_{03}\right) \\
m_{2} s_{2} g \sin \left(\theta_{1}\right)+m_{3} s_{3} g \sin \left(\theta_{1}+\theta_{2}\right)+m_{3} s_{2} g \sin \left(\theta_{1}\right)+k_{11}\left(s_{1}+(1 / 2) \theta_{1}-s_{01}\right)(1 / 2) \\
+k_{21}\left(s_{1}-(1 / 2) \theta_{1}-s_{01}\right)(-1 / 2) \\
m_{3} s_{3} g \sin \left(\theta_{1}+\theta_{2}\right)+k_{12}\left(s_{2}+(1 / 2) \theta_{2}-s_{02}\right)(1 / 2)+k_{22}\left(s_{2}-(1 / 2) \theta_{2}-s_{02}\right)(-1 / 2) \\
k_{13}\left(s_{3}+(1 / 2) \theta_{3}-s_{03}\right)(1 / 2)+k_{23}\left(s_{3}-(1 / 2) \theta_{3}-s_{03}\right)(-1 / 2)
\end{array}\right]
$$




\subsection{Design PID Controller}

Design of a linear methodology to control of continuum robot manipulator was very straight forward. Since there was an output from the torque model, this means that there would be two inputs into the PID controller. Similarly, the outputs of the controller result from the two control inputs of the torque signal. In a typical PID method, the controller corrects the error between the desired input value and the measured value. Since the actual position is the measured signal. Figure 2 is shown linear PID methodology, applied to continuum robot manipulator [21-34].

$e(t)=\theta_{a}(t)-\theta_{d}(t)$

$U_{P I D}=K_{p_{a}} e+K_{V_{a}} \dot{e}+K_{I} \sum e$

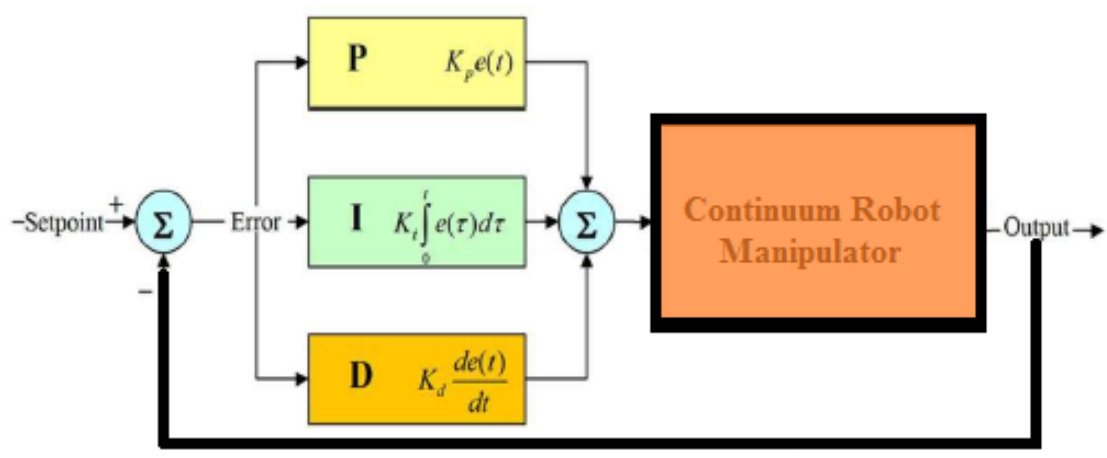

Fig 2: Block diagram of linear PID method

The model-free control strategy is based on the assumption that the joints of the manipulators are all independent and the system can be decoupled into a group of single-axis control systems [35-43]. Therefore, the kinematic control method always results in a group of individual controllers, each for an active joint of the manipulator. With the independent joint assumption, no a priori knowledge of robot manipulator dynamics is needed in the kinematic controller design, so the complex computation of its dynamics can be avoided and the controller design can be greatly simplified. This is suitable for real-time control applications when powerful processors, which can execute complex algorithms rapidly, are not accessible. However, since joints coupling is neglected, control performance degrades as operating speed increases and a manipulator controlled in this way is only appropriate for relatively slow motion [44- 53]. The fast motion requirement results in even higher dynamic coupling between the various robot joints, which cannot be compensated for by a standard robot controller such as PID [50], and hence model-based control becomes the alternative. 


\subsection{Feedback Linearization Compensate}

The central idea of Feedback linearization compensator (FLC) is feedback linearization methodology. It has assumed that the desired motion trajectory for the continuum robot manipulator $\mathrm{q}_{d}(\mathrm{t})$, as determined, by a path planner. Defines the tracking error as:

$e(t)=q_{d}(t)-q_{a}(t)$

Where e(t) is error of the plant, $\boldsymbol{q}_{\boldsymbol{d}}(\boldsymbol{t})$ is desired input variable, that in our system is desired displacement, $\boldsymbol{q}_{\boldsymbol{a}}(\boldsymbol{t})$ is actual displacement. If an alternative linear state-space equation in the form $\dot{\boldsymbol{x}}=\boldsymbol{A} \boldsymbol{x}+\boldsymbol{B} \boldsymbol{U}$ can be defined as

$\dot{x}=\left[\begin{array}{ll}0 & I \\ 0 & 0\end{array}\right] x+\left[\begin{array}{l}0 \\ I\end{array}\right] U$

With $\boldsymbol{U}=-\boldsymbol{D}^{-\mathbf{1}}(\boldsymbol{q}) \cdot \boldsymbol{N}(\boldsymbol{q}, \dot{\boldsymbol{q}})+\boldsymbol{D}^{-\mathbf{1}}(\boldsymbol{q}) \cdot \boldsymbol{\tau}$ and this is known as the Brunousky canonical form. By equation (18) and (19) the Brunousky canonical form can be written in terms of the state $\boldsymbol{x}=\left[\boldsymbol{e}^{T} \dot{\boldsymbol{e}}^{T}\right]^{T}$ as [35-44]

$$
\frac{d}{d t}\left[\begin{array}{l}
e \\
\dot{e}
\end{array}\right]=\left[\begin{array}{ll}
0 & I \\
0 & 0
\end{array}\right] \cdot\left[\begin{array}{l}
e \\
\dot{e}
\end{array}\right]+\left[\begin{array}{l}
0 \\
I
\end{array}\right] U
$$

With

$$
U=\ddot{q}_{d}+D^{-1}(q) \cdot\{N(q \cdot \dot{q})-\tau\}
$$

Then compute the required arm torques using inverse of equation (23), is;

$\tau=D(q)\left(\ddot{q}_{d}-U\right)+N(\dot{q}, q)$

This is a nonlinear feedback control law that guarantees tracking of desired trajectory. Selecting proportionalplus-derivative (PD) feedback for $\mathrm{U}(\mathrm{t})$ results in the PD-feedback linearization compensator [45-53];

$\tau=D(q)\left(\ddot{q}_{d}+K_{v} \dot{e}+K_{p} e\right)+N(q, \dot{q})$

and the resulting linear error dynamics are

$\left(\ddot{q}_{d}+K_{v} \dot{e}+K_{p} e\right)=0$

According to the linear system theory, convergence of the tracking error to zero is guaranteed [6]. Where $\mathrm{K}_{\mathrm{p}}$ and $\mathrm{K}_{\mathrm{v}}$ are the controller gains. The result schemes is shown in Figure 3, in which two feedback loops, 
namely, inner loop and outer loop, which an inner loop is a compensate loop and an outer loop is a tracking error loop.

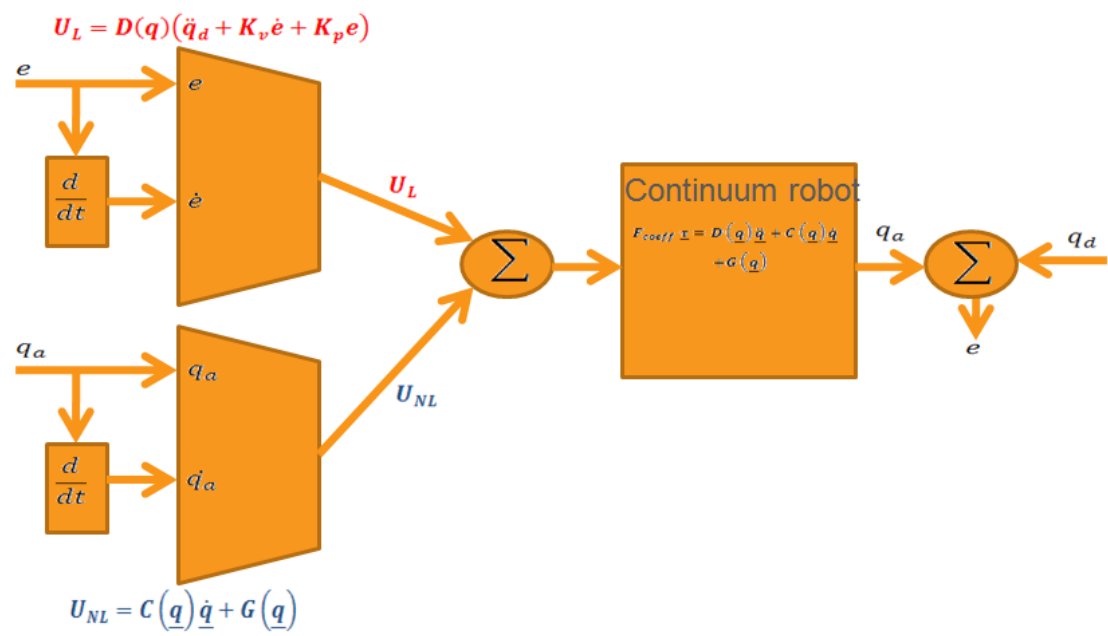

Fig 3: Block diagram of PD-feedback linearization compensator (PD-FLC)

\section{Fuzzy Inference Engine}

This section provides a review about foundation of fuzzy logic based on [32, 53]. Supposed that $U$ is the universe of discourse and $x$ is the element of $U$, therefore, a crisp set can be defined as a set which consists of different elements $(x)$ will all or no membership in a set. A fuzzy set is a set that each element has a membership grade, therefore it can be written by the following definition;

$A=\left\{x, \mu_{A}(x) \mid x \in X\right\} ; A \in U$

Where an element of universe of discourse is $\mathrm{x}, \mu_{\mathrm{A}}$ is the membership function (MF) of fuzzy set. The membership function $\left(\mu_{\mathrm{A}}(\mathrm{x})\right)$ of fuzzy set $\mathrm{A}$ must have a value between zero and one. If the membership function $\mu_{\mathrm{A}}(\mathrm{x})$ value equal to zero or one, this set change to a crisp set but if it has a value between zero and one, it is a fuzzy set. Defining membership function for fuzzy sets has divided into two main groups; namely; numerical and functional method, which in numerical method each number has different degrees of membership function and functional method used standard functions in fuzzy sets. The membership function which is often used in practical applications includes triangular form, trapezoidal form, bell-shaped form, and Gaussian form.

Linguistic variable can open a wide area to use of fuzzy logic theory in many applications (e.g., control and system identification). In a natural artificial language all numbers replaced by words or sentences.

If - then Rule statements are used to formulate the condition statements in fuzzy logic. A single fuzzy If - then rule can be written by 
where $A$ and $B$ are the Linguistic values that can be defined by fuzzy set, the If - part of the part of " $x$ is $A$ " is called the antecedent part and the then - part of the part of " $y$ is $B$ " is called the Consequent or Conclusion part. The antecedent of a fuzzy if-then rule can have multiple parts, which the following rules shows the multiple antecedent rules:

if $e$ is $N B$ and $\dot{e}$ is $M L$ then $T$ is $L L$

where $e$ is error, $\dot{e}$ is change of error, $N B$ is Negative Big, $M L$ is Medium Left, $T$ is torque and $L L$ is Large Left. If - then rules have three parts, namely, fuzzify inputs, apply fuzzy operator and apply implication method which in fuzzify inputs the fuzzy statements in the antecedent replaced by the degree of membership, apply fuzzy operator used when the antecedent has multiple parts and replaced by single number between 0 to 1 , this part is a degree of support for the fuzzy rule, and apply implication method used in consequent of fuzzy rule to replaced by the degree of membership. The fuzzy inference engine offers a mechanism for transferring the rule base in fuzzy set which it is divided into two most important methods, namely, Mamdani method and Sugeno method. Mamdani method is one of the common fuzzy inference systems and he designed one of the first fuzzy controllers to control of system engine. Mamdani's fuzzy inference system is divided into four major steps: fuzzification, rule evaluation, aggregation of the rule outputs and defuzzification. Michio Sugeno use a singleton as a membership function of the rule consequent part. The following definition shows the Mamdani and Sugeno fuzzy rule base

Mamdani F.R $R^{1}$ if $\quad x$ is $A$ and $y$ is $B$ then $\quad z$ is $C$

Sugeno F. $R^{1}$ if $\quad x$ is $A$ and $y$ is $B$ then $\quad f(x, y)$ is $C$

When $\mathrm{x}$ and $\mathrm{y}$ have crisp values fuzzification calculates the membership degrees for antecedent part. Rule evaluation focuses on fuzzy operation (AND/OR ) in the antecedent of the fuzzy rules. The aggregation is used to calculate the output fuzzy set and several methodologies can be used in fuzzy logic controller aggregation, namely, Max-Min aggregation, Sum-Min aggregation, Max-bounded product, Max-drastic product, Max-bounded sum, Max-algebraic sum and Min-max. Two most common methods that used in fuzzy logic controllers are Max-min aggregation and Sum-min aggregation. Max-min aggregation defined as below

$\mu_{U}\left(x_{k}, y_{k}, U\right)=\mu_{\cup_{i=1}^{r} F R^{i}}\left(x_{k}, y_{k}, U\right)=\max \left\{\min _{i=1}^{r}\left[\mu_{R p q}\left(x_{k}, y_{k}\right), \mu_{p_{m}}(U)\right]\right\}$

The Sum-min aggregation defined as below

$\mu_{U}\left(x_{k}, y_{k}, U\right)=\mu_{\mathrm{U}_{i=1}^{r} F R^{i}}\left(x_{k}, y_{k}, U\right)=\sum \min _{i=1}^{r}\left[\mu_{R p q}\left(x_{k}, y_{k}\right), \mu_{p_{m}}(U)\right]$

where $r$ is the number of fuzzy rules activated by $x_{k}$ and $y_{k}$ and also $\mu_{\cup_{i=1}^{r} F R^{i}}\left(x_{k}, y_{k}, U\right)$ is a fuzzy interpretation of $i-t h$ rule. Defuzzification is the last step in the fuzzy inference system which it is used to transform fuzzy set to crisp set. Consequently defuzzification's input is the aggregate output and the defuzzification's output is a crisp number. Centre of gravity method (COG) and Centre of area method (COA) are two most common defuzzification methods, which COG method used the following equation to calculate the

defuzzification 
$\operatorname{COG}\left(x_{k}, y_{k}\right)=\frac{\sum_{i} U_{i} \sum_{j=1}^{r} \cdot \mu_{u}\left(x_{k}, y_{k}, U_{i}\right)}{\sum_{i} \sum_{j=1}^{r} \cdot \mu_{u}\left(x_{k}, y_{k}, U_{i}\right)}$

and $C O A$ method used the following equation to calculate the defuzzification

$\operatorname{COA}\left(x_{k}, y_{k}\right)=\frac{\sum_{i} U_{i} \cdot \mu_{u}\left(x_{k}, y_{k}, U_{i}\right)}{\sum_{i} \mu_{U} \cdot\left(x_{k}, y_{k}, U_{i}\right)}$

Where $\operatorname{COG}\left(\mathrm{x}_{\mathrm{k}}, \mathrm{y}_{\mathrm{k}}\right)$ and $\operatorname{COA}\left(\mathrm{x}_{\mathrm{k}}, \mathrm{y}_{\mathrm{k}}\right)$ illustrates the crisp value of defuzzification output, $\mathrm{U}_{\mathrm{i}} \in \mathrm{U}$ is discrete element of an output of the fuzzy set, $\mu_{\mathrm{U}} \cdot\left(\mathrm{x}_{\mathrm{k}}, \mathrm{y}_{\mathrm{k}}, \mathrm{U}_{\mathrm{i}}\right)$ is the fuzzy set membership function, and $\mathrm{r}$ is the number of fuzzy rules.

Based on foundation of fuzzy logic methodology; fuzzy logic controller has played important rule to design nonlinear controller for nonlinear and uncertain systems [53]. However the application area for fuzzy control is really wide, the basic form for all command types of controllers consists of;

- Input fuzzification (binary-to-fuzzy[B/F]conversion)

- Fuzzy rule base (knowledge base)

- Inference engine

- Output defuzzification (fuzzy-to-binary[F/B]conversion).

\section{Methodology}

Based on the dynamic formulation of continuum robot manipulator, (3), and the industrial PID law (5) in this paper we discuss about regulation problem, the desired position is constant, i.e., $\dot{q}_{d}=0$. In most continuum robot manipulator control, desired joint positions are generated by the trajectory planning. The objective of continuum robot control is to design the input torque in (1) such that the tracking error

$e=q_{d}-q_{a}$

When the dynamic parameters of robot formulation known, the PID control formulation (25) should include a compensator as

$\tau=-k_{p} e-k_{d} e-K_{i} \sum e+(G+F)$

Where $\mathrm{G}$ is gravity and $\mathrm{F}$ is appositive definite diagonal matrix friction term (coulomb friction). If we use a Lyapunov function candidate as

$V_{p i d}=\frac{1}{2} \dot{q}^{T} M \dot{q}+\frac{1}{2} e^{T} k_{p} e$

$\dot{V}_{\text {pid }}=-\dot{q}^{T} k_{d} \dot{q} \leq 0$ 
It is easy to known $\dot{q}=0$ and $e=0$ are only initial conditions in $\Omega=\{[\dot{q}, e]: \dot{V}=0\}$, for which $[\dot{q}, e] \in \Omega$ for al $1 t \leq 0$. By the LaSalle's invariance principle, $e \rightarrow 0$ and $\dot{e} \rightarrow 0$. When $\mathrm{G}$ and $\mathrm{F}$ in (25) are unknown, a fuzzy logic can be used to approximate them as

$f(x)=\sum_{l=1}^{M} \theta^{l} \mathcal{E}^{l}(x)=\theta^{T} \mathcal{E}(x)$

Where $\quad \theta=\left(\theta^{1}, \ldots, \theta^{M}\right)^{T}, \mathcal{E}(x)=\left(\mathcal{E}^{1}(x), \ldots, \mathcal{E}^{M}(x)\right)^{T}$, and $\mathcal{E}^{l}(x)=: \prod_{i=1}^{n} \frac{{ }^{\mu} A_{i}^{l}\left(x_{i}\right)}{} \sum_{l=1}^{M}\left(\prod_{i=1}^{n} \mu_{A_{i}^{l}}\left(x_{i}\right)\right)$. $\theta^{1}, \ldots, \theta^{M}$ are adjustable parameters in (39). $\mu_{A_{1}^{1}}\left(x_{1}\right), \ldots, \mu_{A_{n}^{m}}\left(x_{n}\right)$ are given membership functions whose parameters will not change over time.

The second type of fuzzy systems is given by

$f(x)=\frac{\sum_{l=1}^{M} \theta^{l}\left[\prod_{i=1}^{n} \exp \left(-\left(\frac{x_{i}-\alpha_{i}^{l}}{\delta_{i}^{l}}\right)^{2}\right)\right]}{\sum_{l=1}^{M}\left[\prod_{i=1}^{n} \exp \left(-\left(\frac{x_{i}-\alpha_{i}^{l}}{\delta_{i}^{l}}\right)^{2}\right)\right]}$

Where $\theta^{l}, \alpha_{i}^{l}$ and $\delta_{i}^{l}$ are all adjustable parameters. From the universal approximation theorem, we know that we can find a fuzzy system to estimate any continuous function. For the first type of fuzzy systems, we can only adjust $\theta^{l}$ in (60). We define $f^{\wedge}(x \mid \theta)$ as the approximator of the real function $f(x)$.

$f^{\wedge}(x \mid \theta)=\theta^{T} \varepsilon(x)$

We define $\theta^{*}$ as the values for the minimum error:

$\theta^{*}=\arg \min _{\theta \in \Omega}\left[\sup _{x \in U}\left|f^{\wedge}(x \mid \theta)-g(x)\right|\right]$

Where $\Omega$ is a constraint set for $\theta$. For specific $x, \sup _{x \in U}\left|f^{\wedge}\left(x \mid \theta^{*}\right)-f(x)\right|$ is the minimum approximation error we can get.

We used the first type of fuzzy systems (39) to estimate the nonlinear system (26) the fuzzy formulation can be write as below;

$$
\begin{aligned}
f(x \mid \theta) & =\theta^{T} \varepsilon(x) \\
& =\frac{\sum_{l=1}^{n} \theta^{l}\left[\mu_{A} l(x)\right]}{\sum_{l=1}^{n}\left[\mu_{A} l(x)\right]}
\end{aligned}
$$

Where $\theta^{1}, \ldots, \theta^{n}$ are adjusted by an adaptation law.

This method has two main controller's coefficients, $K_{p}$ and $K_{V}$. To tune and optimize these parameters mathematical formulation is used 
$U$

$=\left(U_{f u z z y}+U_{\text {lin }}\right)$

$\times U_{P I D}$

$\left.U=U_{f u z z y}+U_{l i n}\right) \times U_{P I D}=[D(C+G)]+D(q)\left(\ddot{q}_{d}+K_{v} \dot{e}+K_{p} e\right)+\frac{\sum_{l=1}^{M} \theta^{l}\left[\Pi_{i=1}^{n} \exp \left(-\left(\frac{x_{i}-\alpha_{i}^{l}}{\delta_{i}^{l}}\right)^{2}\right)\right]}{\sum_{l=1}^{M}\left[\prod_{i=1}^{n} \exp \left(-\left(\frac{x_{i^{-}-\alpha_{i}^{l}}{ }^{2}}{\delta_{i}^{l}}\right)^{2}\right)\right]} \times$

$\left(K_{p_{a}} e+K_{V_{a}} \dot{e}+K_{I} \sum e\right)$

The most important different between $P D \times F L C$ and $P D \times F L C+f u z z y$ inference system is the uncertainty. In $P D \times F L C$ the uncertainty is $d=G+F+f$. The feedback linearization gain must be bigger than its upper bound. It is not an easy job because this term includes tracking errors $e_{1}$ and $\dot{q}_{1}$. While in PD $\times F L C+$ fuzzy inference system, the uncertainty $\eta$ is the fuzzy approximation error for $G+F+f$.

$$
G+F+f=\frac{\sum_{l=1}^{M} \theta^{l}\left[\prod_{i=1}^{n} \exp \left(-\left(\frac{x_{i}-\alpha_{i}^{l}}{\delta_{i}^{l}}\right)^{2}\right)\right]}{\sum_{l=1}^{M}\left[\prod_{i=1}^{n} \exp \left(-\left(\frac{x_{i}-\alpha_{i}^{l}}{\delta_{i}^{l}}\right)^{2}\right)\right]}
$$

It is usually is smaller than $G+F+f$; and the upper bound of it is easy to be estimated. Figure 4 shows the PID controller with serial PD fuzzy feedback linearization compensator.

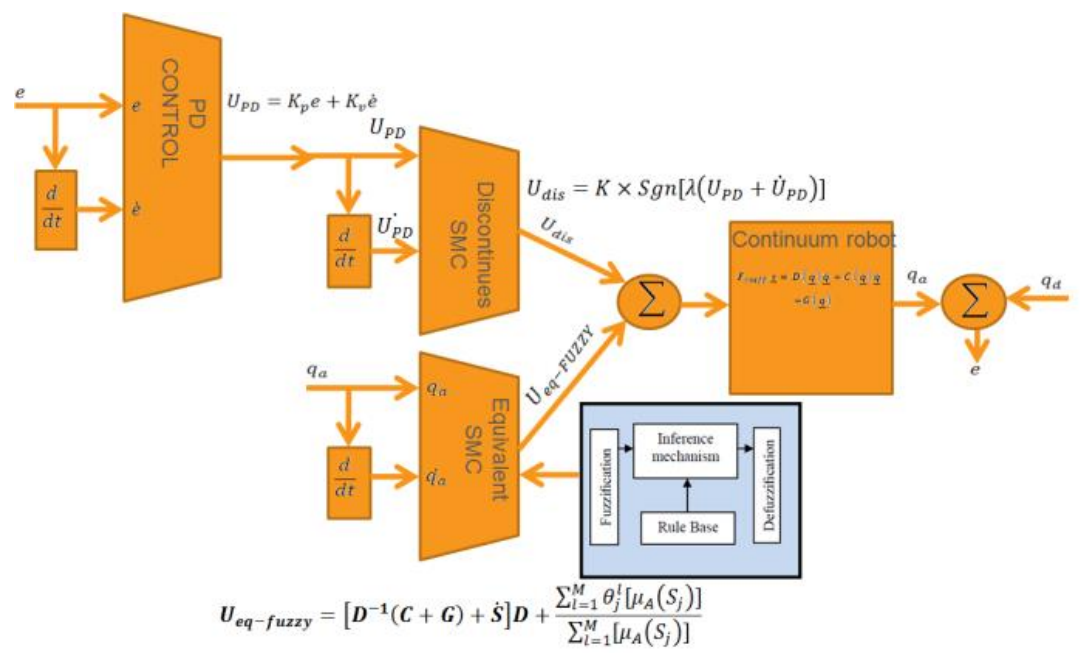

Fig 4: PID with fuzzy FLC 


\section{Results And Discussion}

Linear PID controller (PID) and proposed PD fuzzy feedback linearization estimator were tested to step response trajectory. The simulation was implemented in MATLAB/SIMULINK environment. Position trajectory and disturbance rejection are compared in these controllers.

Position trajectory: Figure 5 shows the links trajectory in PID controller and proposed PID fuzzy feedback linearization estimator without disturbance for step trajectory in general and zoom scaling.
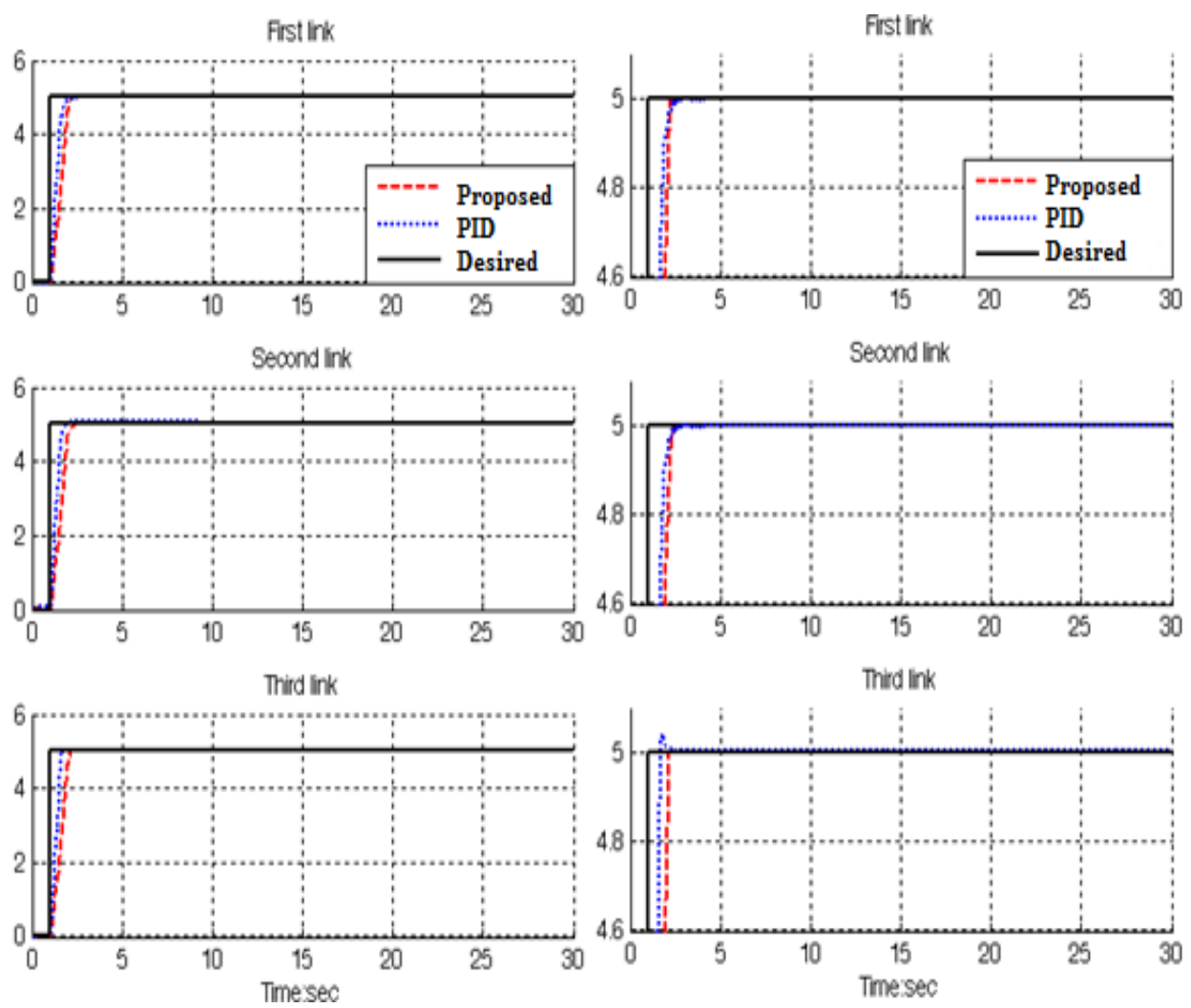

Fig 5: PID controller Vs. Proposed method

By comparing sinus response, Figure 6, in PD controller and PID with Fuzzy FLC, we can seen the the proposed controller's overshoot $\mathbf{( 0 \% )}$ ) is lower than PID's $\mathbf{( 2 . 8 \% )}$.

Disturbance rejection: Figure 6 is indicated the power disturbance removal in PID controller and PID Fuzzy FLC. Besides a band limited white noise with predefined of $30 \%$ the power of input signal is applied to the step PID controller and proposed method; it found slight oscillations in PID position responses. 

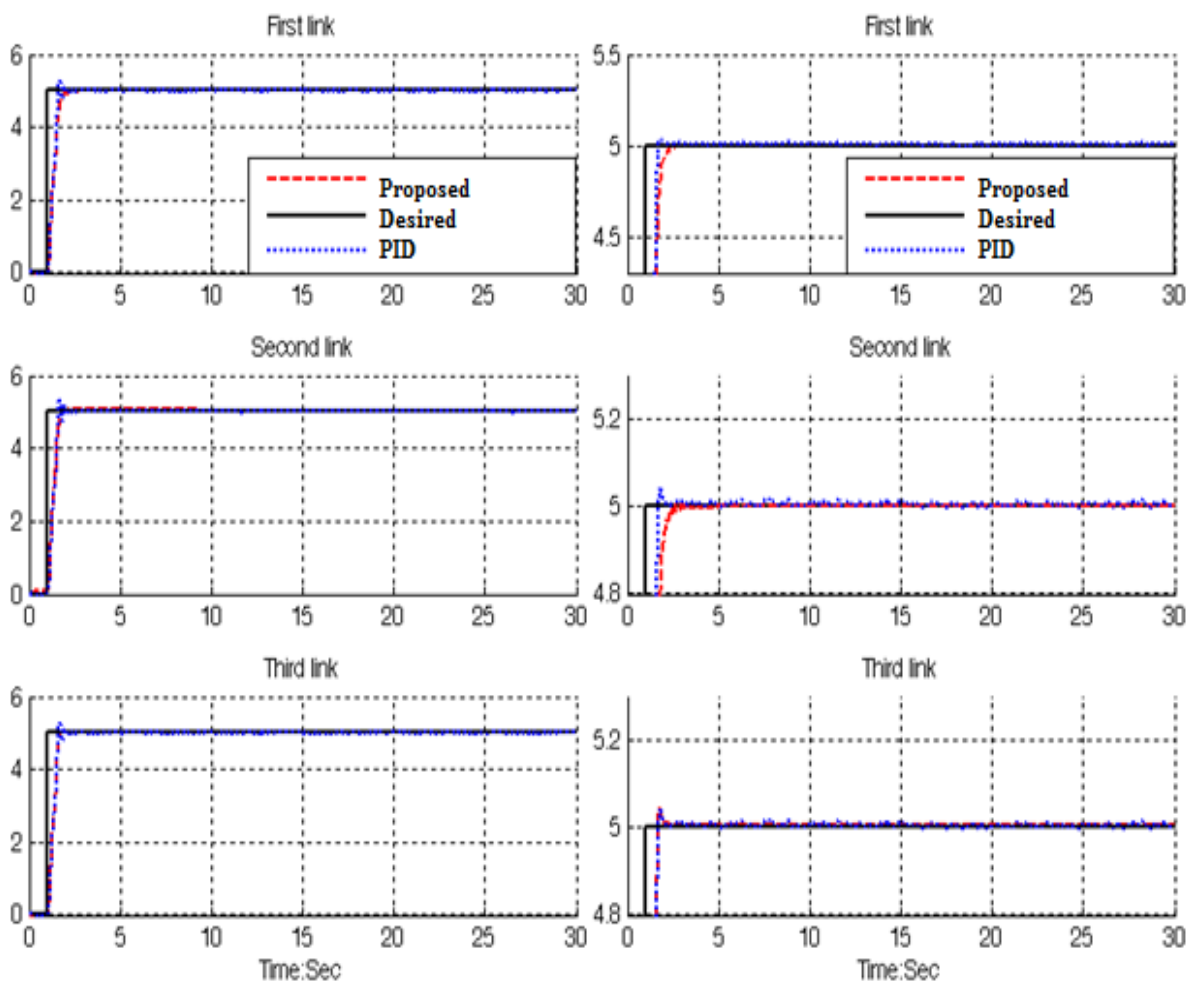

Fig 6: PID Vs. Proposed method: Continuum robot arm with external disturbance

Among above graph, relating to step trajectory following with external disturbance, PID controller has slightly fluctuations. By comparing overshoot; proposed controller's overshoot $\mathbf{( 2 . 3 \% )}$ is lower than PID's $(16 \%)$.

\section{Conclusion}

Refer to the research, a PID main controller with fuzzy parallel feedback linearization estimator design and application to continuum robot arm has proposed in order to design high performance nonlinear estimator in the presence of highly uncertainties and external disturbances. Regarding to the positive points in linear PID controller, parallel feedback linearization method and fuzzy inference system it is found that the fuzzy logic laws derived in the Lyapunov sense. The stability of the closed-loop system is proved mathematically based on the Lyapunov method. The main target in this work is compensating the model uncertainty by fuzzy inference system, in the case of continuum robot arm. In finally part parallel fuzzy feedback linearization compensator is used to compensate and adjusted the linear PID controller. In this case the performance is improved by using the advantages of nonlinear feedback linearization method and artificial intelligence compensate while the disadvantages removed by added each method to previous method. 


\section{Acknowledgment}

The authors would like to thank the anonymous reviewers for their careful reading of this paper and for their helpful comments. This work was supported by the SSP Research and Development Corporation Program of Iran under grant no. 20132014-Persian Gulf-1A.

\section{References}

[1] T. R. Kurfess, Robotics and automation handbook: CRC, 2005.

[2] J. J. E. Slotine and W. Li, Applied nonlinear control vol. 461: Prentice hall Englewood Cliffs, NJ, 1991.

[3] K. Ogata, Modern control engineering: Prentice Hall, 2009.

[4] J. J. D'Azzo, C. H. Houpis and S. N. Sheldon, Linear control system analysis and design with MATLAB: CRC, 2003.

[5] B. Siciliano and O. Khatib, Springer handbook of robotics: Springer-Verlag New York Inc, 2008.

[6] F. T. Cheng, T. L. Hour, Y. Y. Sun and T. H. Chen, "Study and resolution of singularities for a 6-DOF PUMA manipulator," Systems, Man, and Cybernetics, Part B: Cybernetics, IEEE Transactions on, No. 2, vol. 27, pp. 332-343, 2002.

[7] M. W. Spong and M. Vidyasagar, Robot dynamics and control: Wiley-India, 2009.

[8] A. Vivas and V. Mosquera, "Predictive functional control of a PUMA robot," Conference Proceedings, 2005.

[9] D. Nguyen-Tuong, M. Seeger and J. Peters, "Computed torque control with nonparametric regression models," IEEE conference proceeding, 2008, pp. 212-217.

[10] Farzin Piltan , N. Sulaiman, Zahra Tajpaykar, Payman Ferdosali, Mehdi Rashidi, "Design Artificial Nonlinear Robust Controller Based on CTLC and FSMC with Tunable Gain," International Journal of Robotic and Automation, 2 (3): 205-220, 2011.

[11] Farzin Piltan, A. R. Salehi and Nasri B Sulaiman.," Design artificial robust control of second order system based on adaptive fuzzy gain scheduling," world applied science journal (WASJ), 13 (5): 10851092, 2011.

[12] Farzin Piltan, N. Sulaiman, Atefeh Gavahian, Samira Soltani, Samaneh Roosta, "Design Mathematical Tunable Gain PID-Like Sliding Mode Fuzzy Controller with Minimum Rule Base," International Journal of Robotic and Automation, 2 (3): 146-156, 2011.

[13] Farzin Piltan, M. Akbari, M. Piran, M. Bazrega "Design Model Free Switching Gain Scheduling Baseline Controller with Application to Automotive Engine," International Journal of Information Technology and Computer Science (IJITCS), 5 (1): 65-76, 2013.

[14] Farzin Piltan, M. Piran, M. Bazregar, M. Akbari "Design High Impact Fuzzy Baseline Variable Structure Methodology to Artificial Adjust Fuel Ratio ," International Journal of Intelligent Systems and Applications (IJISA), 5 (2): 59-70, 2013.

[15] Farzin Piltan, N. Sulaiman, Arash Zargari, Mohammad Keshavarz, Ali Badri , "Design PID-Like Fuzzy Controller With Minimum Rule Base and Mathematical Proposed On-line Tunable Gain: Applied to Robot Manipulator," International Journal of Artificial intelligence and expert system, 2 (4):184-195, 2011.

[16] Farzin Piltan, Nasri Sulaiman, M. H. Marhaban and R. Ramli, "Design On-Line Tunable Gain Artificial Nonlinear Controller," Journal of Advances In Computer Research, 2 (4): 75-83, 2011.

[17] Farzin Piltan, N. Sulaiman, Payman Ferdosali, Iraj Assadi Talooki, "Design Model Free Fuzzy Sliding Mode Control: Applied to Internal Combustion Engine," International Journal of Engineering, 5 (4):302$312,2011$. 
[18] Farzin Piltan, N. Sulaiman, Samaneh Roosta, M.H. Marhaban, R. Ramli, "Design a New Sliding Mode Adaptive Hybrid Fuzzy Controller," Journal of Advanced Science \& Engineering Research , 1 (1): 115 $123,2011$.

[19] Farzin Piltan, Atefe Gavahian, N. Sulaiman, M.H. Marhaban, R. Ramli, "Novel Sliding Mode Controller for robot manipulator using FPGA," Journal of Advanced Science \& Engineering Research, 1 (1): 1-22, 2011.

[20] Farzin Piltan, N. Sulaiman, A. Jalali \& F. Danesh Narouei, "Design of Model Free Adaptive Fuzzy Computed Torque Controller: Applied to Nonlinear Second Order System," International Journal of Robotics and Automation, 2 (4):232-244, 2011.

[21] Farzin Piltan, N. Sulaiman, Iraj Asadi Talooki, Payman Ferdosali, "Control of IC Engine: Design a Novel MIMO Fuzzy Backstepping Adaptive Based Fuzzy Estimator Variable Structure Control ," International Journal of Robotics and Automation, 2 (5):360-380, 2011.

[22] Farzin Piltan, N. Sulaiman, Payman Ferdosali, Mehdi Rashidi, Zahra Tajpeikar, "Adaptive MIMO Fuzzy Compensate Fuzzy Sliding Mode Algorithm: Applied to Second Order Nonlinear System," International Journal of Engineering, 5 (5): 380-398, 2011.

[23] Farzin Piltan, N. Sulaiman, Hajar Nasiri, Sadeq Allahdadi, Mohammad A. Bairami, "Novel Robot Manipulator Adaptive Artificial Control: Design a Novel SISO Adaptive Fuzzy Sliding Algorithm Inverse Dynamic Like Method," International Journal of Engineering, 5 (5): 399-418, 2011.

[24] Samira Soltani \& Farzin Piltan, "Design Artificial Nonlinear Controller Based on Computed Torque like Controller with Tunable Gain”. World Applied Science Journal,14 (9): 1306-1312, 2011.

[25] Farzin Piltan, N. Sulaiman, Sadeq Allahdadi, Mohammadali Dialame, Abbas Zare, "Position Control of Robot Manipulator: Design a Novel SISO Adaptive Sliding Mode Fuzzy PD Fuzzy Sliding Mode Control," International Journal of Artificial intelligence and Expert System, 2 (5):208-228, 2011.

[26] Farzin Piltan, SH. Tayebi HAGHIGHI, N. Sulaiman, Iman Nazari, Sobhan Siamak, "Artificial Control of PUMA Robot Manipulator: A-Review of Fuzzy Inference Engine And Application to Classical Controller ," International Journal of Robotics and Automation, 2 (5):401-425, 2011.

[27] Farzin Piltan, N. Sulaiman, Abbas Zare, Sadeq Allahdadi, Mohammadali Dialame, "Design Adaptive Fuzzy Inference Sliding Mode Algorithm: Applied to Robot Arm," International Journal of Robotics and Automation , 2 (5): 283-297, 2011.

[28] Farzin Piltan, Amin Jalali, N. Sulaiman, Atefeh Gavahian, Sobhan Siamak, "Novel Artificial Control of Nonlinear Uncertain System: Design a Novel Modified PSO SISO Lyapunov Based Fuzzy Sliding Mode Algorithm ," International Journal of Robotics and Automation, 2 (5): 298-316, 2011.

[29] Farzin Piltan, N. Sulaiman, Amin Jalali, Koorosh Aslansefat, "Evolutionary Design of Mathematical tunable FPGA Based MIMO Fuzzy Estimator Sliding Mode Based Lyapunov Algorithm: Applied to Robot Manipulator," International Journal of Robotics and Automation, 2 (5):317-343, 2011.

[30] Farzin Piltan, N. Sulaiman, Samaneh Roosta, Atefeh Gavahian, Samira Soltani, "Evolutionary Design of Backstepping Artificial Sliding Mode Based Position Algorithm: Applied to Robot Manipulator," International Journal of Engineering, 5 (5):419-434, 2011.

[31] Farzin Piltan, N. Sulaiman, S.Soltani, M. H. Marhaban \& R. Ramli, "An Adaptive sliding surface slope adjustment in PD Sliding Mode Fuzzy Control for Robot Manipulator," International Journal of Control and Automation , 4 (3): 65-76, 2011.

[32] Farzin Piltan, N. Sulaiman, Mehdi Rashidi, Zahra Tajpaikar, Payman Ferdosali, "Design and Implementation of Sliding Mode Algorithm: Applied to Robot Manipulator-A Review ," International Journal of Robotics and Automation, 2 (5):265-282, 2011.

[33] Farzin Piltan, N. Sulaiman, Amin Jalali, Sobhan Siamak, and Iman Nazari, "Control of Robot Manipulator: Design a Novel Tuning MIMO Fuzzy Backstepping Adaptive Based Fuzzy Estimator Variable Structure Control ,’ International Journal of Control and Automation, 4 (4):91-110, 2011. 
[34] Farzin Piltan, N. Sulaiman, Atefeh Gavahian, Samaneh Roosta, Samira Soltani, "On line Tuning Premise and Consequence FIS: Design Fuzzy Adaptive Fuzzy Sliding Mode Controller Based on Lyaponuv Theory," International Journal of Robotics and Automation, 2 (5):381-400, 2011.

[35] Farzin Piltan, N. Sulaiman, Samaneh Roosta, Atefeh Gavahian, Samira Soltani, "Artificial Chattering Free on-line Fuzzy Sliding Mode Algorithm for Uncertain System: Applied in Robot Manipulator," International Journal of Engineering, 5 (5):360-379, 2011.

[36] Farzin Piltan, N. Sulaiman and I.AsadiTalooki, "Evolutionary Design on-line Sliding Fuzzy Gain Scheduling Sliding Mode Algorithm: Applied to Internal Combustion Engine," International Journal of Engineering Science and Technology, 3 (10):7301-7308, 2011.

[37] Farzin Piltan, Nasri B Sulaiman, Iraj Asadi Talooki and Payman Ferdosali.," Designing On-Line Tunable Gain Fuzzy Sliding Mode Controller Using Sliding Mode Fuzzy Algorithm: Applied to Internal Combustion Engine," world applied science journal (WASJ), 15 (3): 422-428, 2011.

[38] Farzin Piltan and Shahnaz Tayebi Haghighi, "Design Gradient Descent Optimal Sliding Mode Control of Continuum Robot, IAES-International Journal of Robotics and Automation, No.4, Vol. 1, pp. 175189, 2012.

[39] M. Bazregar, Farzin Piltan, A. Nabaee and M. Ebrahimi, " Parallel Soft Computing Control Optimization Algorithm for Uncertainty Dynamic Systems," International Journal of Advanced Science and Technology (IJAST), Vol. 51, pp. 93-106, 2013.

[40] Farzin Piltan, N. Sulaiman, M. H. Marhaban, Adel Nowzary, Mostafa Tohidian," "Design of FPGA based sliding mode controller for robot manipulator," International Journal of Robotic and Automation, 2 (3): 183-204, 2011.

[41] Farzin Piltan, M. Mirzaie, F. Shahriyari, Iman Nazari \& S. Emamzadeh.” Design Baseline Computed Torque Controller" International Journal of Engineering, 3(3): 2012.

[42] Farzin Piltan, H. Rezaie, B. Boroomand, Arman Jahed," Design robust back stepping online tuning feedback linearization control applied to IC engine," International Journal of Advance Science and Technology, 42: 183-204, 2012.

[43] Farzin Piltan, I. Nazari, S. Siamak, P. Ferdosali ,'Methodology of FPGA-based mathematical errorbased tuning sliding mode controller" International Journal of Control and Automation, 5(1): 89-110, 2012.

[44] Farzin Piltan, M. A. Dialame, A. Zare, A. Badri ,'Design Novel Lookup table changed Auto Tuning FSMC: Applied to Robot Manipulator" International Journal of Engineering, 6(1): 25-40, 2012.

[45] Farzin Piltan, B. Boroomand, A. Jahed, H. Rezaie ,"Methodology of Mathematical Error-Based Tuning Sliding Mode Controller" International Journal of Engineering, 6(2): 96-112, 2012.

[46] Farzin Piltan, F. Aghayari, M. R. Rashidian, M. Shamsodini, "A New Estimate Sliding Mode Fuzzy Controller for Robotic Manipulator" International Journal of Robotics and Automation, 3(1): 45-58, 2012.

[47] Farzin Piltan, M. Keshavarz, A. Badri, A. Zargari , "Design novel nonlinear controller applied to robot manipulator: design new feedback linearization fuzzy controller with minimum rule base tuning method" International Journal of Robotics and Automation, 3(1): 1-18, 2012.

[48] Piltan, F., et al. "Design sliding mode controller for robot manipulator with artificial tunable gain". Canaidian Journal of pure and applied science, 5 (2), 1573-1579, 2011.

[49] Farzin Piltan, A. Hosainpour, E. Mazlomian, M.Shamsodini, M.H Yarmahmoudi. "Online Tuning Chattering Free Sliding Mode Fuzzy Control Design: Lyapunov Approach" International Journal of Robotics and Automation, 3(3): 2012.

[50] Farzin Piltan , M.H. Yarmahmoudi, M. Shamsodini, E.Mazlomian, A.Hosainpour. " PUMA-560 Robot Manipulator Position Computed Torque Control Methods Using MATLAB/SIMULINK and Their Integration into Graduate Nonlinear Control and MATLAB Courses" International Journal of Robotics and Automation, 3(3): 2012. 
[51] Farzin Piltan, R. Bayat, F. Aghayari, B. Boroomand. "Design Error-Based Linear Model-Free Evaluation Performance Computed Torque Controller" International Journal of Robotics and Automation, 3(3): 2012.

[52] Farzin Piltan, S. Emamzadeh, Z. Hivand, F. Shahriyari \& Mina Mirazaei . " PUMA-560 Robot Manipulator Position Sliding Mode Control Methods Using MATLAB/SIMULINK and Their Integration into Graduate/Undergraduate Nonlinear Control, Robotics and MATLAB Courses" International Journal of Robotics and Automation, 3(3): 2012.

[53] Farzin Piltan, J. Meigolinedjad, S. Mehrara, S. Rahmdel. " Evaluation Performance of $2^{\text {nd }}$ Order Nonlinear System: Baseline Control Tunable Gain Sliding Mode Methodology" International Journal of Robotics and Automation, 3(3): 2012.

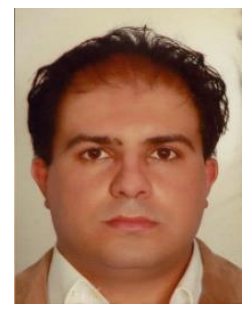

Farzin Piltan was born on 1975, Shiraz, Iran. In 2004 he is jointed the research and development company, SSP Co, Shiraz, Iran. In addition to 7 textbooks, Farzin Piltan is the main author of more than 70 scientific papers in refereed journals. He is editorial board of international journal of control and automation (IJCA), editorial board of International Journal of Intelligent System and Applications (IJISA), editorial board of IAES international journal of robotics and automation, editorial board of International Journal of Reconfigurable and Embedded Systems and reviewer of (CSC) international journal of robotics and automation. His main areas of research interests are nonlinear control, artificial control system and applied to FPGA, robotics and artificial nonlinear control and IC engine modelling and control.

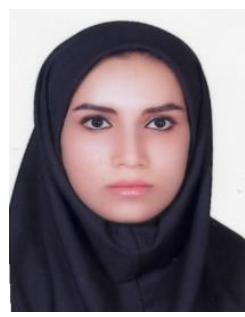

Sara Emamzadeh is a control and automation engineer researcher of research and development company SSP. Co. She is an expert in artificial intelligence and control engineer in this company. Her research activities deal with the robotic control, artificial intelligence and expert system.

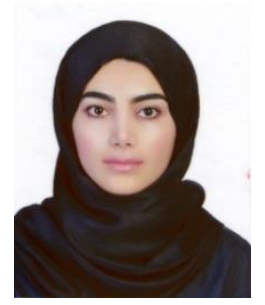

Sara Heidari is a mathematical control researcher of research and development company SSP. Co. She is an expert in control, artificial intelligence and expert systems in this company. Her research activities deal with the robotic control, artificial intelligence and expert system. 


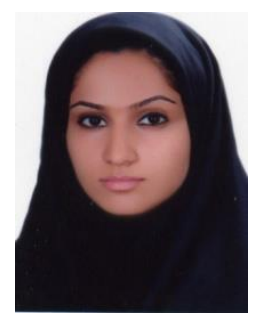

Samaneh Zahmatkesh is an Electronic engineer researcher of research and development company SSP. Co. She is an expert in control engineer, artificial intelligence and expert systems in this company. Her research activities deal with the robotic control, artificial intelligence and expert system.

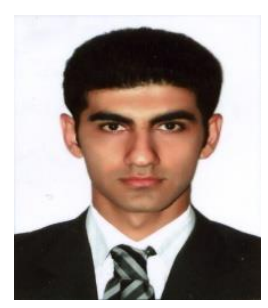

Kamran Heidari is a researcher of research and development company SSP. Co. His research activities deal with the robotic control, artificial intelligence and expert system.

How to cite this paper: Farzin Piltan,Sara Emamzadeh,Sara Heidari,Samaneh Zahmatkesh,Kamran Heidari,"Design Artificial Intelligent Parallel Feedback Linearization of PID Control with Application to Continuum Robot", IJEM, vol.3, no.2, pp.51-72, 2013.DOI: 10.5815/ijem.2013.02.04 